\title{
Comparison of Shisha Smoking Behavior among Medical and Pharmacy Students
}

\author{
Ashok Kumar', Salman Baig1, Sana Ansari', Nadeem Rizvi', Huma Sharif', \\ Anwar Ejaz Beg1, Ammara Rauf1, Faraz Ahmed Baig1, Ammara Abdul Majeed ${ }^{2}$ \\ ${ }^{1}$ Ziauddin Hospital, Karachi, Pakistan \\ ${ }^{2}$ Sindh Medical College, Karachi, Pakistan \\ Email: ashoka_pj@yahoo.com
}

Received 15 April 2016; accepted 2 July 2016; published 5 July 2016

Copyright (C) 2016 by authors and Scientific Research Publishing Inc.

This work is licensed under the Creative Commons Attribution International License (CC BY).

http://creativecommons.org/licenses/by/4.0/

(c) (i) Open Access

\begin{abstract}
Background: Health care workers are respected in every society and have a strong influence on the behaviour of the community. In order to reduce the shisha dependence in the Pakistani population, it is necessary to evaluate the perspective of future doctors and pharmacists regarding this addiction as they become role models for the future generations. Objective: The aim is to compare the knowledge, attitudes, and practices of shisha use among medical students and pharmacy students in order to assess their support in the anti-shisha campaigns of Pakistan. Methodology: Cross sectional study was performed in four major medical universities of Karachi, Pakistan through a modification of the WHO global health survey questionnaire. Result: 398 medical students and 470 pharmacy students were included in the study which showed that currently $9.6 \%$ pharmacy students and $4.8 \%$ medical students used shisha daily $(p=0.000)$. Pharmacy students started shisha use in less than 15 years of age while this number was $29.5 \%$ among medical students $(P=0.000)$. Moreover, $44.6 \%$ pharmacy students and $50 \%$ medical students were not planning to quit this addiction within the next six months. $14 \%$ of pharmacy students and $20.4 \%$ in medical students $(P=0.002)$ were unaware that passive smoking caused lung cancer, while $23.4 \%$ pharmacy students and $33.5 \%$ medical students rejected it as cause of heart diseases $(p=0.006)$. Conclusion: A significant number of medical and pharmacy students were unaware about some of the serious consequences of shisha smoking. Therefore, both groups of students need to be educated about the health hazards of shisha use, in order to control this growing menace.
\end{abstract}

\section{Keywords}

Shisha, Smoking, Tobacco, Students

How to cite this paper: Kumar, A., Baig, S., Ansari, S., Rizvi, N., Sharif, H., Beg, A.E., Rauf, A., Baig, F.A. and Majeed, A.A. (2016) Comparison of Shisha Smoking Behavior among Medical and Pharmacy Students. Journal of Behavioral and Brain Science, 6, 269-279. http://dx.doi.org/10.4236/ibbs.2016.67027 


\section{Introduction}

Just like shisha is known by different names such as hookah, nargile, hubble bubble in different cultures, the origin of this practice is also surrounded by mystery, as various Turkish, Indian and Middle Eastern legends claim to be the source of this popular activity. The history of shisha smoking went back six hundred years ago and therefore had a very exotic image, making it more appealing to the youth, compared to cigarette or pipe smoking [1].

In chemical terms, shisha is another form of tobacco use in which the flavored tobacco is vaporized and passed through a water basin before inhalation. Unlike smoking cigarettes, smoking shisha has developed a milder image with the general population, considering it to have much lesser health risks. This softer image may be attributed to its fruity flavor and bubbly nature, which makes it more comfortable for both females and younger individuals.

The increasing trend of using water pipes can be attributed to the lack of awareness about the health hazards of using shisha. Apart from the social appeal, shisha is also preferred over cigarettes due to its lower cost and smoother texture of smoke [2]. In Pakistan, it has gained immense popularity in the last decade and has become a regular feature at restaurants, cafes and other public places. Apart from the well established medical consequences of tobacco use like cancer, heart disease and pregnancy complications, shisha smoking is also linked to hyperglycemia, hypertriglyceridemia [3] and even periodontal disease [4]. The main reason of the growing usage of shisha smoking is that the users are ignorant about the fact that shisha smoke has greater CO, similar nicotine and much more smoke exposure compared to cigarettes [5]. For this reason, it has developed social acceptability and has the potential of surpassing cigarette smoking in terms of addiction.

Water pipe smoking is popular in youth worldwide and one of the biggest driving forces behind this addiction is peer pressure. Adolescents are usually very impressionable and therefore new trends and fashions are quickest to spread among the youth. Keeping this in mind, the most appropriate youth groups to target are students training in health related fields as they have the background knowledge about the harmful effects of tobacco and can be convinced using scientific evidence and research studies.

Once the addiction kicks in, it becomes tougher to let go and therefore many students keep smoking even after they graduate and begin to practice medicine. A survey conducted on House Officers in Karachi, showed 32\% of all male doctors to be regular smokers [6]. Another study conducted on healthy lifestyle practices in medical and non-medical students also proved that even though the medical students had more awareness, they were less likely to implement these practices in their lives [7].

\section{Methods}

Four universities of Karachi, Pakistan were selected and all available students were given the opportunity to participate in the study. A total of 1150 students were recruited between the periods of December 2014 to February 2015. The universities involved in this study included Ziauddin University, Karachi University, Sindh Jinnah medical university and Dow institute of medical sciences that comprises major portion of medical and pharmacy students in Karachi. All respondents provided verbal consent to participate in the study. Subject matter was approved by Ethical Review Committee of Chest health and education society with reference letter No EC 116/ Chest/2014 before beginning the study.

A self-administered questionnaire from the tobacco initiative, a project of the world health organization, in collaboration with the center for disease control and a number of additional partners, (WHO, 2000) global health professional survey (GHPS) was used with some modification. The validity of modified questionnaire was already checked.

All students who were enrolled in a 4 year medicine or pharmacy degree program and were above the age of 18 , were considered eligible to take part in the study.

Study design was a cross sectional survey and included a 34 question survey. The material included queries about demographic data, current shisha use, motivation to quit and opinion about impact of shisha on health and ways to discourage use. No names were required in the questionnaire (Appendix).

The questionnaire was distributed to the students and requested to fill them then and there. Average time taken to fill out a questionnaire was 10 minutes.

\section{Statistical Analysis}

The sample size was calculated using the formula for calculating sample of prevalence study prevalence as 
$50 \%$ margin of error at $5 \%$ and confidence interval of $95 \%$. Sample size inflated to $20 \%$ taking in consideration wastage and non-response. The sample size was 450 . Statistical analysis was done using statistical package for social sciences version with the help of experienced statistician. Nominal variables such as genders and designations were presented as frequencies and percentages. Chi-square analysis was used to establish if significant association exists between medical and pharmacy student. A p-value $<0.05$ was considered statistically significant

\title{
4. Results
}

Out of 1150 distributed perform as, 868 students responded with a response rate of $75.5 \%$. Of these respondents, 398 (46\%) were medical students and 470 (54\%) were pharmacy students. Gender distribution is summarized in Figure 1.

Figure 1: Gender distribution of study participants.

Occasional shisha smoking was reported in 4.8\% (45) of medical students and 9.6\% (19) of pharmacy students which is a statistically significant difference $(p=0.000)$. Other statistically different responses included age of beginning shisha use, which was less than 15 years in $29.5 \%$ (90) of medical students and $3.6 \%$ (17) of pharmacy students.

Details of the smoking behavior are shown in Table 1 and Table 2 and future plans of smoking cessation are shown in Table 3.

Results of the questions asked to assess the participants' knowledge regarding the hazards of shisha smoking are shown in Table 4 and results of assessment of students' perception towards shisha smoking are shown in Table 5.

Statistically significant results of students' difference in knowledge are displayed in Figure 2.

Statistically significant results of students' difference in perception of Healthcare professional (HCP) role in shisha cessation are displayed in Figure 3.

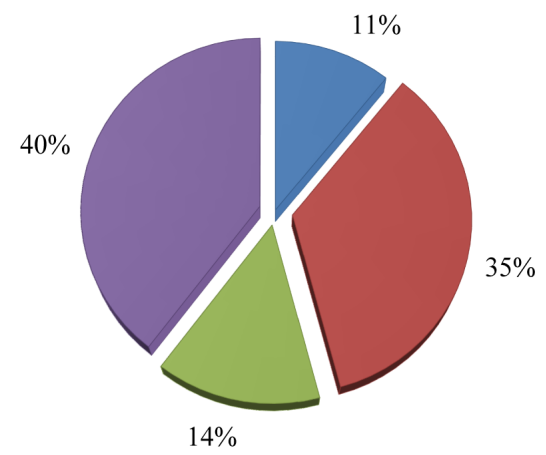

\author{
$\square$ Medical students ( Male) \\ Medical students ( Female) \\ 口Pharmacy students ( Male) \\ 口Pharmacy students ( Female)
}

Figure 1. Gender proportion of particpants from Medical and Pharmacy colleges.

Table 1. Smoking practices in study particpants.

\begin{tabular}{ccc}
\hline & \multicolumn{2}{c}{ Smoking Behavior } \\
\cline { 2 - 3 } Never used Shisha & Pharmacy Students & Medical Students \\
Quit smoking & $354(75.3 \%)$ & $343(86 \%)$ \\
Smoke occasionally & $30(6.4 \%)$ & $16(5.4 \%)$ \\
Smoke both shisha and cigarettes & $45(9.6 \%)$ & $19(4.8 \%)$ \\
Smoke only shisha & $21(4.5 \%)$ & $6(1.5 \%)$ \\
Smoke shisha daily & $14(2.9 \%)$ & $5(1.3 \%)$ \\
Total & $6(1.3 \%)$ & $9(2.3 \%)$ \\
\hline
\end{tabular}

P-value of 0.000 . 


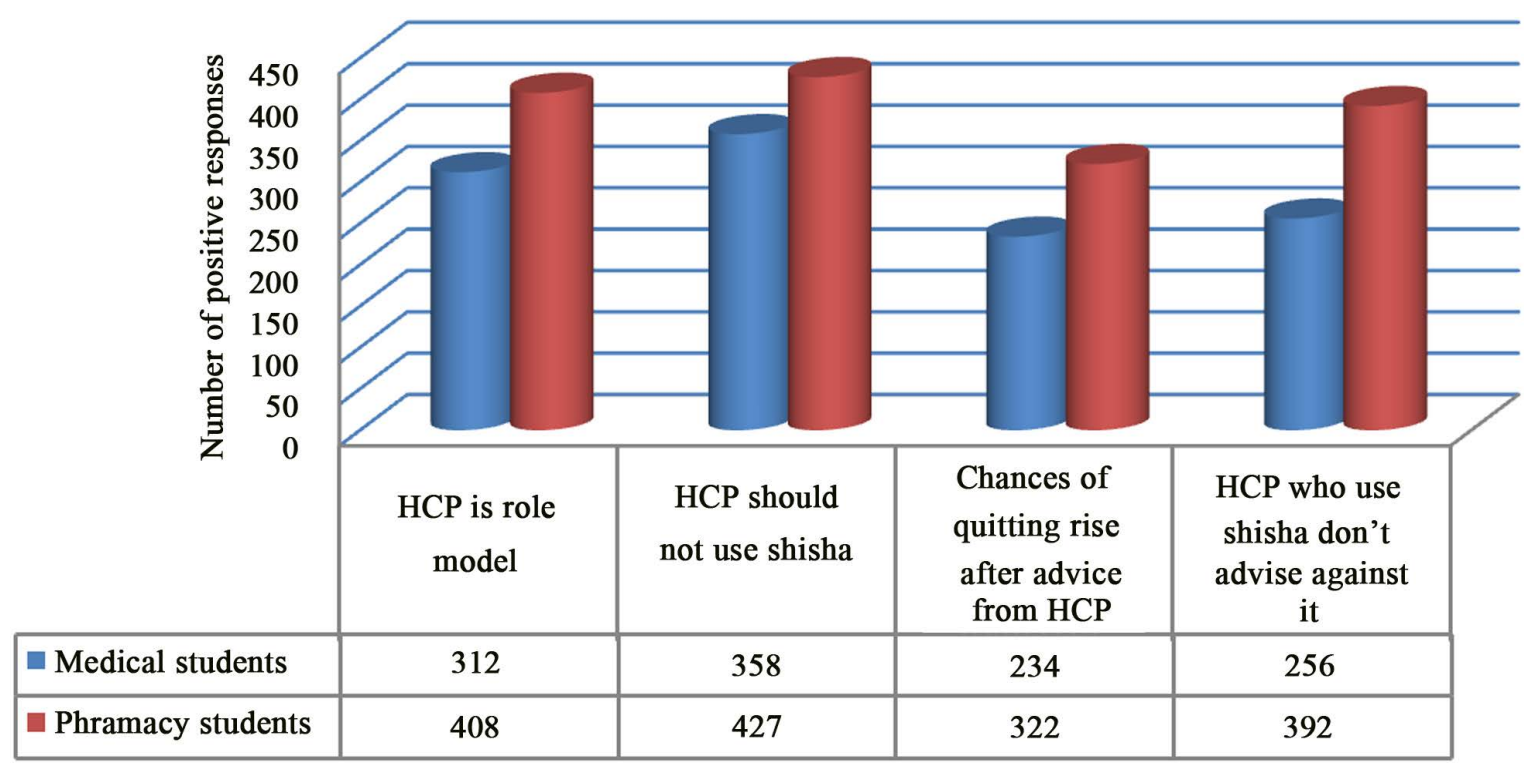

Figure 2. Healthcare provider associated factors related to shisha smoking.

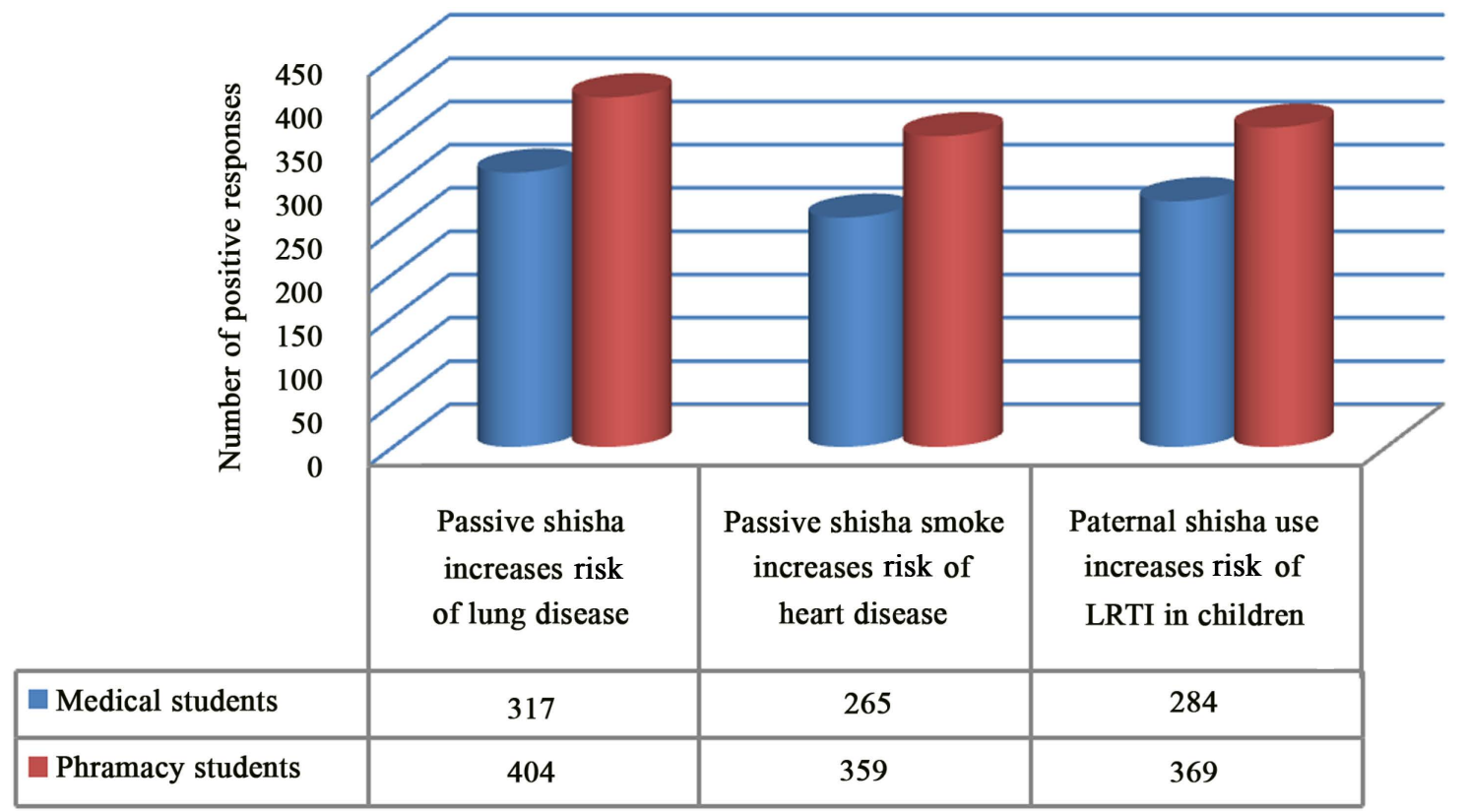

Figure 3. Perception of dangers of passive smoking in participants.

Table 2. Duration of shisha use in study particpants.

\begin{tabular}{|c|c|c|}
\hline & \multicolumn{2}{|c|}{ Smoking Behavior } \\
\hline & Pharmacy Student & Medical Students \\
\hline Less than one hour & $71(82.6 \%)$ & 29 (69\%) \\
\hline One hour or more & $15(17.4 \%)$ & $13(31 \%)$ \\
\hline Total & 86 & 42 \\
\hline
\end{tabular}

P-value 0.08 . 
Table 3. Intention to quit smoking in study particpants.

\begin{tabular}{ccc}
\hline & \multicolumn{2}{c}{ Smoking Behavior } \\
\cline { 2 - 3 } & Pharmacy Student & Medical Students \\
\hline Not ready to quit within next six months & $37(44.6 \%)$ & $19(50 \%)$ \\
Thinking about quitting within six months & $22(26.5 \%)$ & $11(29 \%)$ \\
Ready to quit now & $24(28.9 \%)$ & $8(21 \%)$ \\
Total & 83 & 38 \\
\hline
\end{tabular}

P-value 0.66.

Table 4. Students' knowledge regarding the health hazards of shisha smoking.

\begin{tabular}{|c|c|c|c|c|}
\hline Knowledge parameter & Response & Pharmacy Students & Medical Students & P-value \\
\hline \multirow{3}{*}{ Shisha use is harmful for health } & Agree & 440 & 377 & \multirow{3}{*}{0.624} \\
\hline & Unsure & 20 & 12 & \\
\hline & Disagree & 10 & 9 & \\
\hline \multirow{3}{*}{$\begin{array}{l}\text { Neonatal death is associated } \\
\text { with passive shisha exposure }\end{array}$} & Agree & 298 & 233 & \multirow{3}{*}{0.075} \\
\hline & Unsure & 151 & 154 & \\
\hline & Disagree & 21 & 11 & \\
\hline \multirow{3}{*}{$\begin{array}{l}\text { Maternal shisha use during pregnancy } \\
\text { increases the risk of Sudden } \\
\text { Infant Death Syndrome }\end{array}$} & Agree & 362 & 321 & \multirow{3}{*}{0.289} \\
\hline & Unsure & 103 & 71 & \\
\hline & Disagree & 5 & 6 & \\
\hline \multirow{3}{*}{$\begin{array}{l}\text { Passive shisha smoke increases } \\
\text { the risk of lung disease }\end{array}$} & Agree & 404 & 317 & \multirow{3}{*}{0.002} \\
\hline & Unsure & 50 & 74 & \\
\hline & Disagree & 16 & 7 & \\
\hline \multirow{3}{*}{$\begin{array}{l}\text { Passive shisha use increases } \\
\text { the risk of heart disease }\end{array}$} & Agree & 359 & 265 & \multirow{3}{*}{0.006} \\
\hline & Unsure & 95 & 120 & \\
\hline & Disagree & 15 & 13 & \\
\hline \multirow{3}{*}{$\begin{array}{l}\text { Paternal shisha use increases } \\
\text { the risk of pneumonia in children }\end{array}$} & Agree & 369 & 284 & \multirow{3}{*}{0.38} \\
\hline & Unsure & 92 & 107 & \\
\hline & Disagree & 9 & 7 & \\
\hline
\end{tabular}

Table 5. Students' knowledge regarding the health hazards of shisha smoking.

\begin{tabular}{|c|c|c|c|c|}
\hline Attitude parameter & Response & Pharmacy Students & Medical Students & P-value \\
\hline & Agree & 408 & 312 & \\
\hline \multirow[t]{3}{*}{$\begin{array}{l}\text { Health professionals serve as a role } \\
\text { model for their patients and the public }\end{array}$} & Unsure & 51 & 52 & 0.000 \\
\hline & Disagree & 11 & 34 & \\
\hline & Agree & 427 & 358 & \\
\hline \multirow[t]{2}{*}{$\begin{array}{l}\text { Health professionals should be good } \\
\text { examples by not smoking shisha }\end{array}$} & Unsure & 36 & 23 & 0.028 \\
\hline & Disagree & 7 & 17 & \\
\hline
\end{tabular}




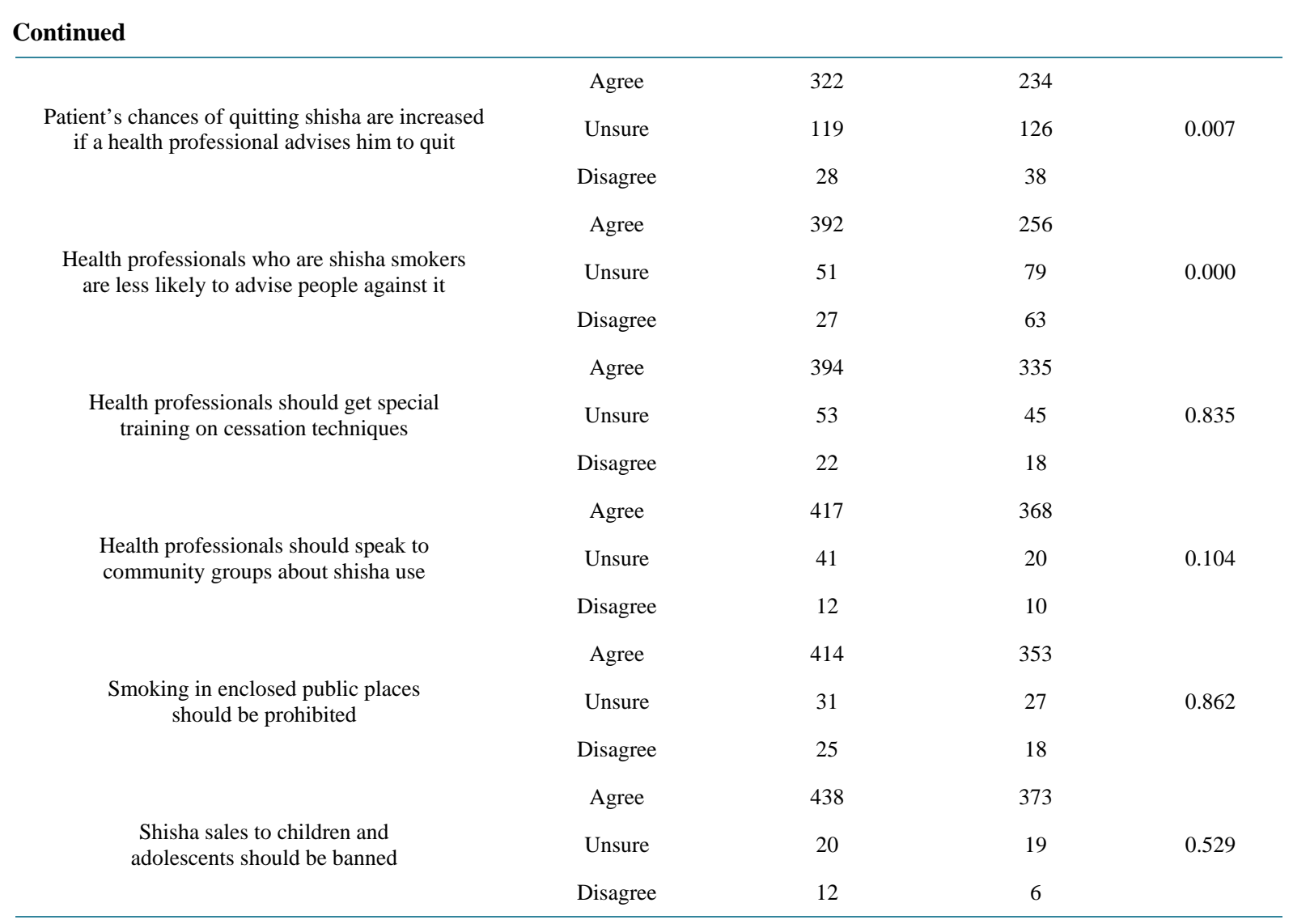

\section{Discussion}

The first step in curbing any dangerous practice is to quantify the prevalence of the health hazard and to analyze the reasons behind it. Once all factors are assessed, solutions can be tailor made to combat the problem.

The use of shisha in adolescents is rampant globally as shown in Table 6.

Worldwide, the waterpipe is enjoyed as a mechanism to relax and unwind. In 2014, the Global Adult Tobaco Survey was conducted in 13 middle to low income countries and it was seen that Vietnam had the highest number of male water pipe users at $13 \%$ whereas in Russia $3 \%$ of the women were regular waterpipe users. [13] Another study conducted on over a thousand sixth and seventh grade students in Lebanon showed a shocking prevalence rate of $44 \%$ [14] whereas a study conducted on university students in Pakistan reported that $60 \%$ of the respondents believed it was safer to smoke shisha than to smoke cigarettes [15].

Our study showed that although pharmacy students had asignificantly higher prevalence of daily (1.3\%) and occasional (9.6\%) shisha smoking, they also had a higher rate of students who had quit smoking (6.4\%) or planned to quit immediately. (28.9\%) Pharmacy students were seen to smoke for a shorter duration, but although medical students smoked less (4.8\%), they smoked for an hour or more with each sitting (31\%). Other studies, like one conducted in China, showed no significant difference between smoking behavior of medical and non medical students [16].

We also report that $75 \%$ of our female participants were smokers which correlate with the well known fact that females tend to choose hookah smoking over cigarette smoking. A study conducted in four Arab countries explored this concept further and concluded that social norms play an important factor on this factor [17].

Pharmacy students participating in our study were better informed about the fact that passive smoking may cause lung and heart disease, but both the medical and pharmacy students had similar levels of knowledge related to other dangers of passive smoking, including risk of neonatal death and Sudden Infant Death Syndrome.

Reasons for this difference could be more detailed study of the detrimental effects of nicotine in the pharmacology curriculum, whereas the multifaceted approach to cardiovascular and lung disease in the medical college may decrease the weight age of the contribution of nicotine to heart and lung disease. 
Table 6. Prevalence rate of shisha smokingin various countries.

\begin{tabular}{cccc}
\hline Country of study & Year of study & Prevalence rate & Reference \\
\hline Pakistan & 2008 & $53.6 \%$ & {$[8]$} \\
Malaysia & 2012 & $20 \%$ & {$[9]$} \\
USA & 2012 & $20 \%$ & {$[10]$} \\
Iran & 2014 & $8.5 \%$ & {$[11]$} \\
Germany & 2015 & $28.9 \%$ & {$[12]$} \\
\hline
\end{tabular}

With such disappointing levels of awareness about the well-known adverse effects of tobacco consumption, it is unreasonable to expect the students to know about recent studies which have shown that hookah smoking leads to a higher exposure to a concentration of heavy metals [18] and produces polycyclic aromatic hydrocarbons, carbon monoxide, and high fraction of small $(<200 \mathrm{~nm})$ particles which form a dangerous bio aerosol which can be hazardous to health when inhaled [19]. Another Pakistani study showed that even passive smokers, exposed to second hand shisha smoke, had significantly higher concentrations of end tidal carbon monoxide levels [20].

The dangers of smoking shisha have been established and the next phase of action is to identify individuals who are at a higher risk of developing serious consequences. The severity of cigarette smoking can be categorized by number of cigarettes smoked, but categorizing the severity of shisha addiction has not yet been standardized. Several options were given by various groups, including the Lebanon Water pipe Dependence Scale which uses an 11 scale questionnaire to discriminate between mild, moderate and heavy shisha smoking [21].

Almost all shisha smokers claim that smoking shisha is relaxing and use it most when hanging out with friends at cafes and restaurants. Medical and pharmacy students are considered to have a higher stress level compared to other university students with higher rates of sleep disorders [22] [23] and psychosomatic symptoms, which is why they can have a higher potential of using a variety of stress busters from energy drinks [24] to pleasure seeking drugs.

In our study, $50 \%$ of medical and $44.6 \%$ of pharmacy students showed no intention to quit smoking in the next six months. This was a better result than a study conducted on Americans with Middle Eastern ethnicity where $73 \%$ of shisha smokers reported no intention to quit smoking. Intention to quit was significantly lower in smokers who had a higher cultural acceptability and longer duration of smoking [25]. In a similar study conducted in India, it was seen that $66.7 \%$ of participants had no intention to quit [26].

Healthier alternatives have been launched to minimize the exposure to tar and nicotine while maintaining the flavor and social context of the activity. One such venture was the launch of e-shisha which was. Unfortunately, the product did not do well in the market as water pipe users did not like the taste [27].

Just like cigarette smoking is now looked down upon, shisha smoking can also be controlled if the general population is informed about its detrimental medical effects and rate of progression towards cancer, heart disease and lung disease. Governments of various countries have established laws to discourage smoking and lay serious penalties upon individuals violating these rules.

In 2002, the Ministry of Health in Pakistan laid down an ordinance whereby public smoking was completely banned. Unfortunately, the implementation of these laws was not enforced properly and people continue to endanger themselves and the people around them by using shisha smoking as a recreational activity. Anti-shisha smoking campaigns should be initiated at a national level, with vigorous advertising at public places where this activity is commonly practiced.

A significant number of students in our study supported an increase in tobacco prices and a legal ban on sale of these products to children. A study conducted in 2010 showed that imposing such legislative bans decreased the incidence of acute coronary syndrome in hospitality workers within six months of the ban [28].

Second hand smoke is not only hazardous for the patrons of public places but also for the staff working there, which has become a major occupational hazard [29]. Media services can also be incorporated with regular advertising, special anti-shisha programs where real life stories can be shared and smokers can be taught different ways of quitting successfully.

The first step in curbing any dangerous practice is to quantify the prevalence of the health hazard and to ana- 
lyze the reasons behind it. Once all factors are assessed, solutions can be tailor made to combat the problem.

Another method of intervention is by involving religious leaders. A study in Egypt showed a high influence of religious leaders on smokers [30] and a similar study in Thailand showed a higher level of abstinence in a small community after an intervention through a monk [31].

There was a unanimous agreement in our study subjects that the general public looks up to health care professionals and that they should be a good example for their patients. Although both groups agreed, pharmacy students had a significantly higher proportion of respondents who emphasized the role of the health care professional. A reason behind the lower enthusiasm within the medical student group might be reluctance to accept responsibility of serving as a role model for the general public.

All respondents agreed that health care professionals should get special training on the obstacles faced by individuals who are trying to quit smoking. Smoking cessation group sessions should be conducted in the community where health care professionals can focus on this growing problem and encourage people to control it before it destroys their medical, financial, social and emotional wellbeing.

\section{Conclusions}

Shisha smoking is gaining more and more popularity in Pakistan and worldwide. The main reason why smokers choose this method over the quick and convenient cigarette smoking is the false belief that shisha is not as injurious to health as cigarette smoking.

Our results show that knowledge and attitude of medicine students is worse than pharmacy students and maximum emphasis should be laid to overcome this ignorance. Along with educational campaigns, other methods of restricting shisha smoking should also be implemented strictly, including increasing taxes and banning shisha cafes.

\section{References}

[1] Jawad, M., Khaki, H. and Hamilton, F. (2012) Shisha Guidance for GPs: Eliciting the Hidden History. British Journal of General Practice, 62, 66-67.

[2] Roskin, J. and Aveyard, P. (2009) Canadian and English Students' Beliefs about Waterpipe Smoking: A Qualitative Study. BMC Public Health, 9, 10. http://dx.doi.org/10.1186/1471-2458-9-10

[3] Aslam, H.M., Saleem, S., German, S. and Qureshi, W.A. (2014) Harmful Effects of Shisha: Literature Review. International Archives of Medicine, 7, 16. http://dx.doi.org/10.1186/1755-7682-7-16

[4] Bibars, A.R., Obeidat, S.R., Khader, Y., Mahasneh, A.M. and Khabour, O.F. (2014) The Effect of Waterpipe Smoking on Periodontal Health. Oral Health \& Preventive Dentistry, 13, 253-259.

[5] Eissenberg, T. and Shihadeh, A. (2009) Waterpipe Tobacco and Cigarette Smoking Direct Comparison of Toxicant Exposure. American Journal of Preventive Medicine, 37, 518-523. http://dx.doi.org/10.1016/j.amepre.2009.07.014

[6] Piryani, R.M. and Rizvi, N. (2004) Smoking Habits amongst House Physicians Working at Jinnah Postgraduate Medical Center, Karachi, Pakistan. Tropical Doctor, 34, 44-45.

[7] Sajwani, R.A., Shoukat, S., Raza, R., Shiekh, M.M., Rashid, Q., Siddique, M.S., et al. (2009) Knowledge and Practice of Healthy Lifestyle and Dietary Habits in Medical and Non-Medical Students of Karachi, Pakistan. Journal of Pakistan Medical Association, 59, 650-655.

[8] Jawaid, A., Zafar, A.M., Rehman, T.U., Nazir, M.R., Ghafoor, Z.A., Afzal, O., et al. (2008) Knowledge, Attitudes and Practice of University Students Regarding Waterpipe Smoking in Pakistan. Tubercle and Lung Disease, 12, 10771084.

[9] Al-Naggar, R.A. and Bobryshev, Y.V. (2012) Shisha Smoking and Associated Factors among Medical Students in Malaysia. Asian Pacific Journal of Cancer Prevention, 13, 5627-5632. http://dx.doi.org/10.7314/APJCP.2012.13.11.5627

[10] Grekin, E.R. and Ayna, D. (2012) Waterpipe Smoking among College Students in the United States: A Review of the Literature. Journal of American College Health, 60, 244-249. http://dx.doi.org/10.1080/07448481.2011.589419

[11] Mohammad Poorasl, A., Abbasi Ghahramanloo, A., Allahverdipour, H. and Modaresi, E.J. (2014) Prevalence of Hookah Smoking in Relation to Religiosity and Familial Support in College Students of Tabriz, Northwest of Iran. Journal of Research in Health Sciences, 14, 268-271.

[12] Kuntz, B. and Lampert, T., KiGGS Study Group (2015) Waterpipe (Shisha) Smoking among Adolescents in Germany: Results of the KiGGS Study: First Follow-Up (KiGGS Wave 1). Bundesgesundheitsblatt Gesundheitsforschung Gesundheitsschutz, 58, 467-473. http://dx.doi.org/10.1007/s00103-015-2128-3 
[13] Morton, J., Song, Y., Fouad, H., Awa, F.E., Abou El Naga, R., Zhao, L., et al. (2014) GATS Collaborative Group Tob Control. Cross-Country Comparison of Waterpipe Use: Nationally Representative Data from 13 Low and Middle-Income. Countries from the Global Adult Tobacco Survey (GATS). 23, 419-427.

[14] Jawad, M., Nakkash, R.T., Mahfoud, Z., Bteddini, D., Haddad, P. and Afifi, R.A. (2015) Parental Smoking and Exposure to Environmental Tobacco Smoke Are Associated with Waterpipe Smoking among Youth: Results from a National Survey in Lebanon. Public Health, 129, 370-376. http://dx.doi.org/10.1016/j.puhe.2015.01.011

[15] Jawaid, A., Zafar, A.M., Rehman, T.U., Nazir, M.R., Ghafoor, Z.A., Afzal, O., et al. (2008) Knowledge, Attitudes and Practice of University Students Regarding Waterpipe Smoking in Pakistan. International Journal of Tuberculosis and Lung Disease, 12, 1077-1084.

[16] Zhu, T., Feng, B., Wong, S., Choi, W. and Zhu, S.H. (2004) A Comparison of Smoking Behaviors among Medical and Other College Students in China. International Journal of Health Promotion and Education, 19, 189-196. http://dx.doi.org/10.1093/heapro/dah206

[17] Khalil, J., Afifi, R., Fouad, F.M., Hammal, F., Jarallah, Y., Mohamed, M. and Nakkash, R. (2013) Women and Waterpipe Tobacco Smoking in the Eastern Mediterranean Region: Allure or Offensiveness. Women Health, 53, 100-116. http://dx.doi.org/10.1080/03630242.2012.753978

[18] Al-Kazwini, A.T., Said, A.J. and Sdepanian, S. (2015) Compartmental Analysis of Metals in Waterpipe Smoking Technique. BMC Public Health, 15, 153. http://dx.doi.org/10.1186/s12889-015-1373-6

[19] Markowicz, P., Löndahl, J., Wierzbicka, A., Suleiman, R., Shihadeh, A. and Larsson, L. (2014) A Study on Particles and Some Microbial Markers in Waterpipe Tobacco Smoke. Science of The Total Environment, 499, 107-113. http://dx.doi.org/10.1016/j.scitotenv.2014.08.055

[20] Akhter, S., Ali Warraich, U., Rizvi, N., Idrees, N. and Zaina, F. (2014) Comparison of End Tidal Carbon Monoxide (eCO) Levels in Shisha (Water Pipe) and Cigarette Smokers. Tobacco Induced Diseases, 12, 10. http://dx.doi.org/10.1186/1617-9625-12-10

[21] Primack, B.A., Khabour, O.F., Alzoubi, K.H., Switzer, G.E., Shensa, A., Carroll, M.V., et al. (2014) The LWDS-10J: Reliability and Validity of the Lebanon Waterpipe Dependence Scale among University Students in Jordan. Nicotine \& Tobacco Research, 16, 915-922. http://dx.doi.org/10.1093/ntr/ntu002

[22] Waqas, A., Khan, S., Sharif, W., Khalid, U. and Ali, A. (2015) Association of Academic Stress with Sleeping Difficulties in Medical Students of a Pakistani Medical School: A Cross Sectional Survey. PeerJ, 3, e840. http://dx.doi.org/10.7717/peerj.840

[23] Cates, M.E., Clark, A., Woolley, T.W. and Saunders, A. (2015) Sleep Quality among Pharmacy Students. The American Journal of Pharmaceutical Education, 79, Article 09. http://dx.doi.org/10.5688/ajpe79109

[24] Aslam, H.M., Mughal, A., Edhi, M.M., Saleem, S., Rao, M.H., Aftab, A., et al. (2013) Assessment of Pattern for Consumption and Awareness Regarding Energy Drinks among Medical students. Archives of Public Health, 71, 31. http://dx.doi.org/10.1186/2049-3258-71-31

[25] Athamneh, L., Sansgiry, S.S., Essien, E.J. and Abughosh, S. (2015) Predictors of Intention to Quit Waterpipe Smoking: A Survey of Arabamericans in Houston. Journal of Addiction, 2015, Article ID: 575479. http://dx.doi.org/10.1155/2015/575479

[26] Kakodkar, P.V. and Bansal, S.S. (2013) Hookah Smoking: Characteristics, Behavior and Perceptions of Youth Smokers in Pune, India. Asian Pacific Journal of Cancer Prevention, 14, 4319-4323. http://dx.doi.org/10.7314/APJCP.2013.14.7.4319

[27] Kotecha, S. and Jawad, M. (2015) Knowledge, Attitudes and Beliefs towards Waterpipe Tobacco Smoking and Electronic Shisha (E-Shisha) among Young Adults in London: A Qualitative Analysis. Primary Health Care Research \& Development 13, 1-9.

[28] Callinan, J.E., Clarke, A., Doherty, K. and Kelleher, C. (2010) Legislative Smoking Bans for Reducing Secondhand Smoke Exposure, Smoking Prevalence and Tobacco Consumption. The Cochrane Database of Systematic Reviews, 14, CD005992. http://dx.doi.org/10.1002/14651858.cd005992.pub2

[29] Kumar, S.R., Davies, S., Weitzman, M. and Sherman, S. (2015) A Review of Air Quality, Biological Indicators and Health Effects of Second-Hand Waterpipe Smoke Exposure. Tobacco Control, 24, i54-i59. http://dx.doi.org/10.1136/tobaccocontrol-2014-052038

[30] Radwan, G.N., Israel, E., El-Setouhy, M., Abdel-Aziz, F., Mikhail, N. and Mohamed, M.K. (2003) Impact of Religious Rulings (Fatwa) on Smoking. Journal of the Egyptian Society of Parasitology, 33, 1087-1101.

[31] Swaddiwudhipong, W., Chaovakiratipong, C., Nguntra, P., Khumklam, P. and Silarug, N. (1993) A Thai Monk: An Agent for Smoking Reduction in a Rural Population. International Journal of Epidemiology, 22, 660-661. http://dx.doi.org/10.1093/ije/22.4.660 


\section{Appendix}

Comparision of Knowledge, Attitude and Practice of Shisha smoking among Medicaland Pharmacy students in Karachi, Pakistan.

All rights reserved by Chest Health and Education Society.

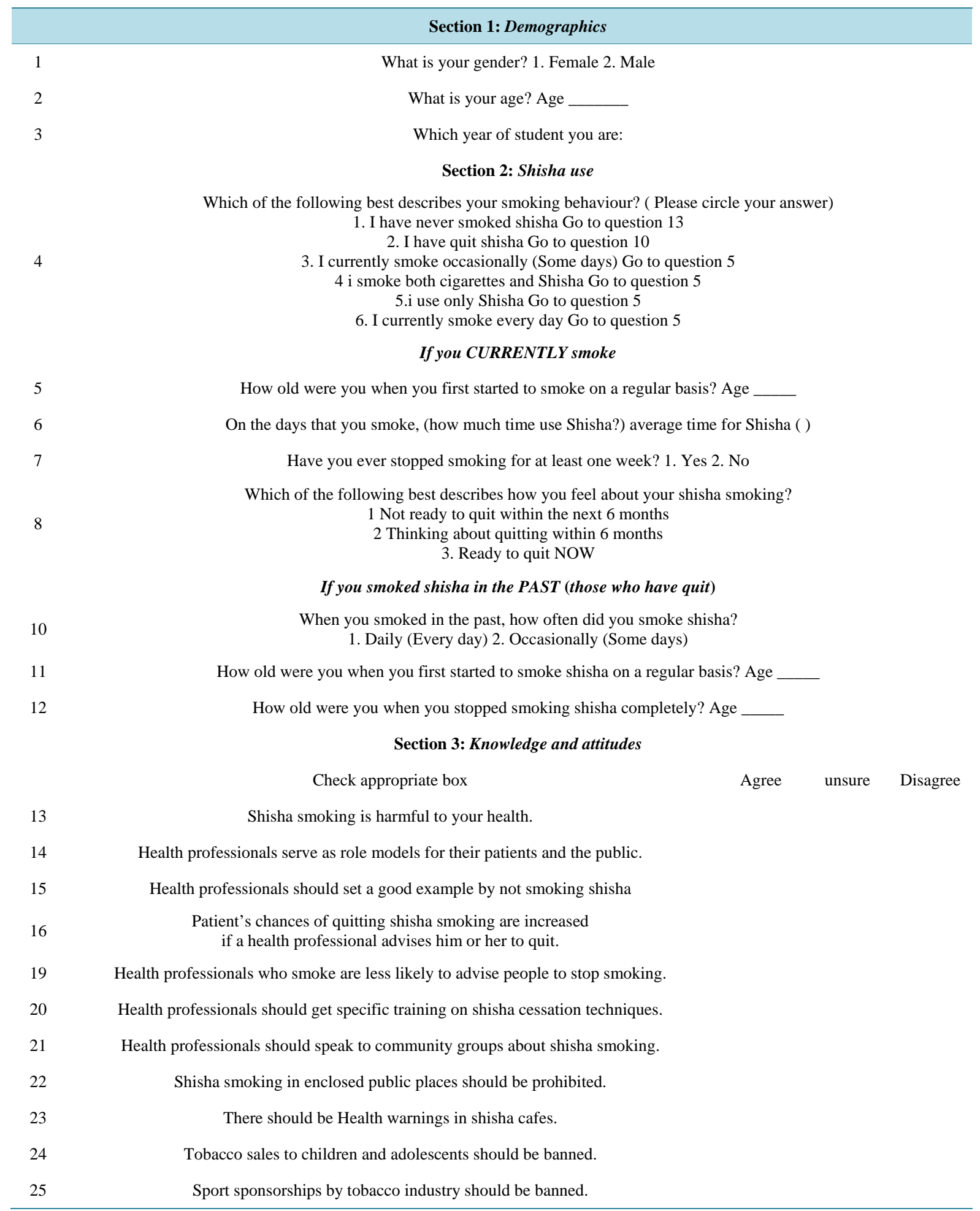




\begin{tabular}{|c|c|}
\hline \multicolumn{2}{|c|}{ Continued } \\
\hline 26 & There should be a complete ban on the advertising of tobacco products. \\
\hline 27 & Hospitals and health care centres should be "smoke-free". \\
\hline 28 & The price of tobacco products should be increased sharply. \\
\hline 29 & Neonatal death is associated with passive smoking. \\
\hline 30 & Maternal smoking during pregnancy increases the risk of Sudden Infant Death Syndrome. \\
\hline 31 & Passive shisha smoking increases the risk of lung disease in non-smoking adults. \\
\hline 32 & Passive shisha smoking increases the risk of heart disease in non-smoking adults. \\
\hline 33 & $\begin{array}{l}\text { Paternal shisha smoking increases the risk of lower respiratory } \\
\text { tract illnesses such as pneumonia in exposed children. }\end{array}$ \\
\hline 34 & $\begin{array}{l}\text { Health professionals should routinely advise patients } \\
\text { who smoke to avoid smoking around children. }\end{array}$ \\
\hline
\end{tabular}

Submit or recommend next manuscript to SCIRP and we will provide best service for you:

Accepting pre-submission inquiries through Email, Facebook, Linkedin, Twitter, etc A wide selection of journals (inclusive of 9 subjects, more than 200 journals)

Providing a 24-hour high-quality service

User-friendly online submission system

Fair and swift peer-review system

Efficient typesetting and proofreading procedure

Display of the result of downloads and visits, as well as the number of cited articles

Maximum dissemination of your research work

Submit your manuscript at: http://papersubmission.scirp.org/ 